\title{
Effectiveness of Extremely Low Frequency Electromagnetic Field and Pulsed Low-Level Laser Therapy in Acute Stroke Treatment
}

\author{
Farzad Ashrafi $^{\circledR}$, Amir Rezaei $^{2^{*}}$, Arash Azhideh $^{1}{ }^{\circledR}$, Faraj Tabei $^{3}{ }^{\circledR}$, Latif Gachkar $^{4}{ }^{\circledR}$, Mehran Arab-Ahmadi $^{\circledR}$, \\ Maryam Yousefi-Ass ${ }^{\circledR}{ }^{\oplus}$, Alireza Zali $^{\circledR}$, Reza Jalili Khoshnoud ${ }^{1}$ \\ ${ }^{1}$ Functional Neurosurgery Research Center, Shahid Beheshti University of Medical Sciences, Tehran, Iran \\ 2Department of Neurology, Shohada-e-Tajrish Hospital, Shahid Beheshti University of Medical Sciences, Tehran, Iran \\ ${ }^{3}$ Department of Nuclear Medicine, Shohada-e-Tajrish Hospital, Shahid Beheshti University of Medical Sciences, Tehran, \\ Iran \\ ${ }^{4}$ Infectious Disease Research Center, Shahid Beheshti University of Medical Sciences, Tehran, Iran. \\ ${ }^{5}$ Advanced Diagnostic and Interventional Radiology Research Center, Tehran University of Medical Sciences, Tehran, Iran \\ ${ }^{6}$ Faculty of Medicine, Shahid Beheshti University of Medical Sciences, Tehran, Iran
}

\begin{abstract}
Introduction: Stroke is one of the most devastating neurologic conditions in the world. Despite all the efforts that have been made for effective treatment, the prevalence of this medical condition is still high. One of the new methods in the treatment of patients is the use of low power laser and pulsed magnetic fields. The previous studies investigated the effectiveness of these methods individually. However, the present study aimed to investigate their effectiveness in combination. Methods: We divided the patients into control $(n=26)$ and experimental $(n=26)$ groups. The primary variables included the Mini-Mental State Examination (MMSE) and the National Institute of Health Stroke Scale (NIHSS). The experimental group received extremely low-frequency electromagnetic field (EMF-ELF) treatment with $1 \mathrm{mT}$ power and laser in rejection with a wavelength of $840 \mathrm{~nm}$ for 5 days and $45 \mathrm{~min} / \mathrm{d}$.

Results: The variable measured during this study, in addition to comparing the results of the intervention between the control and experimental groups, showed a significant difference in all indicators before and after the intervention. The mean and standard deviations of the modified Rankin scale (mRS), functional status (Barthel's index), and cognitive status (MMSE) $(\mathrm{P}<0.001)$ were signed between 2 groups.

Conclusion: Laser and magnetic field combination can be effective in the treatment of stroke. Further studies are recommended to ensure a better comparison.

Keywords: Stroke; Low-level light therapy; Electromagnetic field; Nonablative laser treatments.
\end{abstract}

*Correspondence to Amir Rezaei,

Neurology resident,

Department of Neurology,

Shohada-e-Tajrish Hospital,

Shahid Beheshti University of

Medical Sciences, Tehran, Iran.

Email: Amir1939@gmail.com

Published online June 21, 2020

Citation: Farzad Ashrafi F, Rezaei A, Azhideh A, Tabeie F, Gachkar L, Arab-Ahmadi M, Yousefi-Asl M, Zali A.Effectiveness of Extremely Low Frequency Electromagnetic Field and Pulsed Low-Level Laser Therapy in Acute Stroke Treatment. Clin Neurosci J. 2020;7(3):127131. doi:10.34172/icnj.2020.13.

\section{Introduction}

Extremely low-frequency electromagnetic fields (ELFEMFs) have been developed in laboratories for many years. Exposure to ELF-EMF can affect many cellular structures and compounds, such as the deoxyribonucleic acid in the nucleus, cell reproduction, mechanism of cell death through the cell cycle, metabolism, and the vast majority of protein malfunction. ${ }^{1}$ The outcome of a study focused on oxidative stress of global cerebral ischemia, and reactive oxygen species, demonstrate the possibility of reduction of adverse consequences if ELF-EMF established. $^{2}$

Recent studies suggest that primary rehabilitation therapy by ELF-EMF may be helpful in post-stroke patients. ${ }^{3}$ This method of laser therapy can affect any organism at any level, such as cellular, subcellular, and molecular. ${ }^{4,5}$ This therapy can modify the neural damage caused by the huge levels of oxidative stress. However, its effectiveness has not been utterly evaluated. ${ }^{6,7}$ The neural damage after a brain stroke causes a drastic reduction in the functional situation and cognitive impairment. ${ }^{8}$

It has been found that low-level laser therapy (LLLT) can accentuate the vast majority of biological manners, such as rise in adenosine triphosphate synthesis in mitochondrial respiration, angiogenesis, facilitating wound healing and regeneration in skeletal muscle. ${ }^{9}$ According to the previous

(C) 2020 The Author(s). This is an open access article distributed under the terms of the Creative Commons Attribution License (http:// creativecommons.org/licenses/by/4.0/), which permits unrestricted use, distribution, and reproduction in any medium, provided the original work is properly cited. 
studies, $50 \%$ to $70 \%$ of the reduction was in infarct size 4 to 6 weeks after coronary artery chronic obstruction in the use of LLLT in an experiential model of the infarcted heart. ${ }^{10,11}$ Although there is limited research about the effects of LLLT on stroke, it unveiled its improvements in nervous system processes.

This study aimed to investigate the effect of ELF-EMF and LLLT in combination with post-stroke patients.

\section{Methods}

\section{Patients}

The present study first examined all the patients with acute stroke who were admitted to Shohada Hospital Neurology Ward, Tehran from May 2018 to December 2018. Among these patients, only 52 ones were eligible for the study. Those who did not receive thrombolytic therapy, aged over 18 years, had the first stroke involving only one hemisphere, had symptoms over the last 48 hours, patients with NIHSS (National Institute Of Health Stroke Scale) $>4$, and those who had steady clinical awareness and ability to perform simple voice commands were included in the study. ${ }^{12}$ The exclusion criteria included patients with acute cerebral bleeding, previous history of ischemic and hemorrhagic stroke, history of seizure, lacunar infarction, mRS history $>1$, metal tools inside the body (e.g. cardiac pacemaker), life expectancy less than 3 months, another serious illness that interferes with this treatment and lactating or pregnant women or positive pregnancy test. ${ }^{13}$

\section{Study Design}

This study was designed as a single-blind randomized clinical trial. According to a computer-generated randomization schema, the eligible 52 patients were randomly assigned into 2 groups: Treatment $(n=26)$ and control group $(n=26)$. All patients received standard therapy in both groups, but in the treatment group, they received additional therapy with LLLT method. All of the patients in both groups were informed about the clinical trial and asked to fill the consent form.

Patients were under clinical and radiological examinations 48 hours after the onset of stroke symptoms. Then, after assessing patients for inclusion criteria, they were qualified to enter the study. The treatment was initiated with EMF-ELF at $1 \mathrm{mT} 50 \mathrm{~Hz}$ for 5 days per day from 45 minutes each day and an infrared laser with a wavelength of $840 \mathrm{~nm}$ and 12 watts at 12 different points, similar to the 10-20 electroencephalography system. All of the patients were monitored closely in both groups. The stimulus was discontinued in the treatment group in case of any side effects. Rehabilitation and routine stroke treatments were performed jointly in both groups.

The NIHSS system consists of 11 axes, each axis can score from zero to 2, 3 or 4 points depends on the axis. Maximum 42 and minimum 0 points are possible. A point below 5 can account for the absence or minor stroke symptoms. The points above 5 are divided into threestroke groups: moderate (5-15), moderate to severe (2016), and severe (21-42). ${ }^{14}$

Modified Rankin scale (mRS) measures the severity of the inability to perform daily activities in people with a stroke or other neurological defects. This criterion can vary from zero (asymptomatic) to six (death). ${ }^{13}$ Depression was used in both groups using the Geriatric Depression Scale (GDS). This scale was a 30-item questionnaire completed by each individual. It is divided into three groups: normal (0-9 points), mild depression (19-19 points), and severe depression (2030). ${ }^{15}$ The patient's cognitive status is calculated on the basis of MMSE, which includes 6 areas of orientation, registration, attention, language, recall, and calculation. The maximum score is 30. Points below 24 (19-23) indicate mild intermediate (19-10) and severe (less than 9) cognitive impairment. ${ }^{16}$

Patients were also evaluated for their functional status via the Barthel index for daily living activities. This criterion reflects the level of person's freedom to perform simple and complex activities, as well as the gait of patients. ${ }^{13}$

NIHSS, GDS, MMSE, BI, and side effects were studied, 45 days after the onset of the disease at an outpatient visit in hospital affiliated clinic.

\section{Statistical Analysis}

Data were analyzed via SPSS 16.0 (IBM Crop., Armonk, USA) to compare the qualitative data in two groups, chisquare test or Fisher exact test and quantitative data with independent distribution of $t$ test and normal distribution. Otherwise, the Mann-Whitney test was used. To compare the quantitative data in each group, before and after the intervention, if a normal distribution was used, the paired $t$ test was used and otherwise Wilcoxon test was used. In all cases, the significance limit was placed on $P<0.05$.

\section{Results}

In this study, 52 patients with acute stroke were studied in 2 groups of 26 patients receiving laser and magnetic field and the control group. In cases 17 (65.4\%) and 9 (34.6\%) were male and female respectively versus 10 (38.5\%) male and $16(61.5 \%)$ female in controls. The difference between groups was not significant $(P=0.09)$. The demographic characteristics of patients in the two groups are presented in Table 1. Based on the Kolmogorov-Smirnov test, all quantitative variables followed normal distribution before and after the intervention except for mRS before the intervention and in the control group (Table 2). The mean age \pm standard deviation in the experimental group was $63.5 \pm 14.3$ years and in the control group was $65.9 \pm 15.7$ years, the mean and standard deviation of body mass index (BMI) in the experimental group 
Table 1. The demographic characteristics of patients among cases and control groups

\begin{tabular}{lccc}
\hline Variable & Case & Control & $\boldsymbol{P}$ Value \\
\hline Hypertension & $21(80.8 \%)$ & $22(84.6 \%)$ & 1 \\
Hyperlipidemia & $15(57.7 \%)$ & $14(53.8 \%)$ & $9(34.6 \%)$ \\
Diabetes & $7(26.9 \%)$ & $13(50 \%)$ & 0.76 \\
Smoking & $10(38.5 \%)$ & $17(65.4 \%)$ & 0.58 \\
Anti-platelets & $16(61.5 \%)$ & $4(15.4 \%)$ \\
Antidepressant before intervention & $6(23.1 \%)$ & & 0.73 \\
Origin & & $9(34.6 \%)$ \\
Right anterior & $8(30.8 \%)$ & $1(4 \%)$ \\
Right posterior & $6(23.1 \%)$ & $13(50 \%)$ \\
Left anterior & $7(26.9 \%)$ & $3(11.5 \%)$ \\
Lateral posterior & $5(19.2 \%)$ & 0.16 \\
\hline
\end{tabular}

Table 2. Distribution of Acute Stroke Patients Receiving Laser Along the Magnetic Field and Their Control Group in Terms of Underlying Variables and Interfering With the Result of the Kolmogorov-Smirnov Test

\begin{tabular}{|c|c|c|c|c|}
\hline Variables & Controls & $P$ Value & Cases & $P$ Value \\
\hline $\mathrm{BMI}, \mathrm{kg} / \mathrm{m}^{2}$ & $31.2 \pm 3.8$ & 0.41 & $30.2 \pm 2.7$ & 0.79 \\
\hline NIHSS before, $\mathrm{kg} / \mathrm{m}^{2}$ & $8.5 \pm 3.3$ & 0.38 & $8.4 \pm 3.3$ & 0.86 \\
\hline NIHSS after, $\mathrm{kg} / \mathrm{m}^{2}$ & $7.2 \pm 3.1$ & 0.58 & $5.9 \pm 3.3$ & 0.58 \\
\hline BARTHEL before, $\mathrm{Kg} / \mathrm{m}^{2}$ & $9.4 \pm 2$ & 0.58 & $10.1 \pm 2.5$ & 0.45 \\
\hline BARTHEL after, $\mathrm{kg} / \mathrm{m}^{2}$ & $13.3 \pm 2.2$ & 0.49 & $15 \pm 2.2$ & 0.68 \\
\hline $\mathrm{mRS}$ before, $\mathrm{kg} / \mathrm{m}^{2}$ & $2.6 \pm 0.8$ & $<0.01$ & $2.7 \pm 2.7$ & 0.05 \\
\hline $\mathrm{mRS}$ after, $\mathrm{kg} / \mathrm{m}^{2}$ & $2.5 \pm 0.6$ & $<0.01$ & $1.6 \pm 0.8$ & 0.07 \\
\hline GDS before, $\mathrm{kg} / \mathrm{m}^{2}$ & $11.3 \pm 2.5$ & 0.49 & $12 \pm 2.2$ & 0.92 \\
\hline GDS after, $\mathrm{kg} / \mathrm{m}^{2}$ & $9.1 \pm 2.4$ & 0.43 & $6.4 \pm 2.2$ & 0.58 \\
\hline MMSE after, $\mathrm{kg} / \mathrm{m}^{2}$ & $23 \pm 2.3$ & 0.45 & $23.1 \pm 2.1$ & 0.75 \\
\hline MMSE before, $\mathrm{kg} / \mathrm{m}^{2}$ & $24.1 \pm 1.9$ & 0.31 & $25.3 \pm 2.2$ & 0.25 \\
\hline
\end{tabular}

BMI: body mass index; NIHSS: National Institute of Health Stroke Scale; mRS: modified Rankin scale; GDS; geriatric depression scale; MMSE; mini-mental state examination.

was $30.2 \pm 2.7 \mathrm{~kg} / \mathrm{m}^{2}$ and in the control group $31.2 \pm 3.8$ $\mathrm{kg} / \mathrm{m}^{2}$ and the difference between the groups were not significant. The distribution of the 2 groups for the underlying and intervention variables is shown in Table $2(P=0.57, P=0.26)$. The difference between the 2 groups was not statistically significant in any cases. In other words, the 2 groups were similar in terms of underlying and confounding variables (Table 2 ).

Using independent $t$ test and Mann-Whitney, the difference between 2 groups was not significant for any of the dependent variables before the intervention. In other words, the 2 groups were matched for the dependent variables before the intervention. The independent $t$ test showed that the difference between 2 groups was significant for Barthel's index $(P<0.006)$, GDS $(P<0.001)$, MMSE $(P<0.035)$. The Mann-Whitney test showed that the difference between the 2 groups was the significance $\mathrm{mRS}$ after intervention $(P<0.001)$. In the experimental group, 1 patient began to have a headache (3.8\%) and 3 patients (11.5\%) experienced an unpleasant warmth, while there were no relevant side effects in the control group. After the intervention, the antidepressant treatment was necessary for 6 patients (23.1\%).

In stimulation group and for 8 patients $(30.8 \%)$ in the control group. From this point of view, there are also significant differences between 2 groups $(P=0.76)$. The paired $t$ test in the control group showed that the differences between NIHSS, Barthel's Index, GDS, MMSE variables in the control group were significant before and after the treatment (in all cases $P<0.001$ ). Additionally, Wilcoxon test showed that the difference in mRS before and after the intervention was significant in this group $(P<0.001)$. By paired $t$ test, the difference in NIHSS, Barthel's Index, GDS, MMSE before and after intervention was significant (in all cases $P<0.001$ ) and Wilcoxon test showed that there was a drastic difference in mRS before and after the intervention $(P<0.001)$ (Table 3$)$.

Discussion

Since the onset of stroke, the muscular neural function 
Table 3. Variables Difference Before and After Intervention NIHSS: National Institute Of Health

\begin{tabular}{|c|c|c|c|}
\hline Variables & Groups & & $P$ Value \\
\hline \multirow{2}{*}{ NIHSS } & Cases & $2.5 \pm 0.8$ & $>0.001$ \\
\hline & Controls & $1.35 \pm 0.8$ & $>0.001$ \\
\hline \multirow{2}{*}{ Barthel's index } & Cases & $-5 \pm 1.2$ & $>0.001$ \\
\hline & Controls & $-3.9 \pm 1.5$ & $>0.001$ \\
\hline \multirow{2}{*}{ mRS* } & Cases & - & $>0.001$ \\
\hline & Controls & - & $>0.001$ \\
\hline \multirow{2}{*}{ GDS } & Cases & $5.7 \pm 1$ & $>0.001$ \\
\hline & Controls & $2.2 \pm 1.2$ & $>0.001$ \\
\hline \multirow{2}{*}{ MMSE } & Cases & $-2.2 \pm 0.9$ & $>0.001$ \\
\hline & Controls & $-1 \pm 1.3$ & $>0.001$ \\
\hline
\end{tabular}

NIHSS: National Institute of Health Stroke Scale; mRS: modified Rankin scale; GDS; geriatric depression scale; MMSE; mini-mental state examination. *Wilcoxon Test

has been associated with cognitive impairment and cognitive impairment, problem-solving skills, memory impairment, incomprehensible thinking, and speech impairment. It also includes mental illness, depression, anxiety, emotional instability, and fatigue. ${ }^{17}$ Inpatient physical therapy can greatly reduce post-stroke weakness when established in immediate admission.

Despite the uncertain effects of ELF-EMF, it may produce biological effects, including alterations in ion equilibrium which leads to the uncompensated magnetic spin of free radicals, paramagnetic elements, diamagnetic molecule, and also magnetostrictive and piezoelectric feature in tissue structure. ${ }^{18}$ The main parts of cells and tissues include water, cholesterol, and its derivatives, which form the crystal structure and are affected by the electromagnetic field. ${ }^{19,20}$

In a study on the effect of oxidative stress on rigorous neurorehabilitation in post-acute ischemic stroke, Ciancarelli et $\mathrm{al}^{21}$ demonstrated that vigorous Neurotherapy could decrease oxidative stress and increase endogenous antioxidant arrangement, whereby reducing neurological deficits. Animal research on rats and rabbits showed that transcranial LLLT can improve the neurological outcome after embolic stroke up to 24 and 6 hours, respectively. ${ }^{15}$ The other animal study showed that LLLT did not improve the rabbit's neurological deficits after 24 hours of the stroke. ${ }^{14}$ The different outcomes from various studies might be the result of variety in methods of stroke induction. For instance, using filament or craniotomy in rats against microbeads injection thorough the carotid artery in rabbits. Despite the great effort in studying the bio stimulatory outcomes of CW mode in LLLT, there was not much investigation in the pulsed mode. Moreover, the effect of pulsed mode LLLTs on the attenuation of ischemic tissue was not well studied. Neurogenesis is a mechanism correlated by the attenuation of the behavioral shortages in stroke-induced rats via LLLT. Previous studies on laser mechanism indicated the correlation of heat shock protein upregulation and angiogenic plus antioxidant activity rise, with myogenic cell and ischemic heart tissue. ${ }^{9}$ Additionally, studies showed the upregulation of TGF-1 by LLLT in the ischemic brain, which has a neuroprotective effect while coordinately overcoming NO (nitric oxide) synthase. In 2014, Hacke et $\mathrm{al}^{22}$ had started NEST-3 trial for the efficacy and safety of LLLT on 600 acute stroke patients before 24 hours of starting symptoms. The follow-up time was 90 days, but the trial ended due to lack of positive results. So in $2018 \mathrm{AHA} / \mathrm{ASA}^{23}$ regarding that trial stated that LLLT is not harmful nor effective for acute stroke patients; but due to the positive outcome of our trial, combination of LLLT and EMF-ELF might be effective for acute stroke patients. ${ }^{24}$

The limitations of this study were a short time of stimulation (45 minutes), little follow-up window (45 days), a single-blinded study (observer bias), and limited numbers of patients. Therefore, we suggest further investigation in double-blind multicenter trials with much more stimulation time (up to 120 minutes daily), longer follow-up time (up to 1 year). Also, we suggest that the antioxidant effect of this therapy be measured via lab tests. Due to the meticulous inclusion criteria, many stroke-stricken patients who had severe neurological deficits were eliminated which left us with mild to moderate deficits. Due to the nature of the study, we could not use a placebo or sham.

In conclusion, the combination of laser and magnetic fields can be effective in treating stroke. Further studies are recommended to ensure greater reliability and better comparison.

\section{Future Directions}

Multicenter academic collaboration is a key element to improve our knowledge of the effectiveness of EMF-ELF and LLLT combined on the treatment of acute stroke. EMF-ELF and LLLT are not easily accessible due to the 
high cost. In the next few years' numerous observational studies and treatment trials on acute stroke will increase the level of evidence that currently supports this treatment.

\section{Conflict of Interest}

The authors declare that they have no conflict of interests.

\section{Ethical Statement}

This study was registered at the Iranian Registry of Clinical Trials website (Identifier: IRCT20180913041031N1; https://www.irct.ir/ trial/33991)

\section{References}

1. Lee HC, Hong MN, Jung SH, Kim BC, Suh YJ, Ko YG, et al. Effect of extremely low frequency magnetic fields on cell proliferation and gene expression. Bioelectromagnetics. 2015;36(7):506-16. doi: 10.1002/bem.21932.

2. Dimitrijević D, Savić T, Anđelković M, Prolić Z, Janać B. Extremely low frequency magnetic field $(50 \mathrm{~Hz}, 0.5 \mathrm{mT})$ modifies fitness components and locomotor activity of Drosophila subobscura. Int J Radiat Biol. 2014;90(5):337-43. doi: 10.3109/09553002.2014.888105.

3. Cheng Y, Dai Y, Zhu X, Xu H, Cai P, Xia R, et al. Extremely lowfrequency electromagnetic fields enhance the proliferation and differentiation of neural progenitor cells cultured from ischemic brains. Neuroreport. 2015;26(15):896-902. doi: 10.1097/wnr.0000000000000450.

4. Rubin C. Osteoporosis-Osteopenia-Bone Healing. Arch Oral Biol. 1993:38.

5. Woldańska-Okońska M, Czernicki J. [Effect of low frequency magnetic fields used in magnetotherapy and magnetostimulation on the rehabilitation results of patients after ischemic stroke]. Przegl Lek. 2007;64(2):74-7.

6. Abd-Elsameea AA, Moustaf AA, Mohamed AM. Modulation of the oxidative stress by metformin in the cerebrum of rats exposed to global cerebral ischemia and ischemia/reperfusion. Eur Rev Med Pharmacol Sci. 2014;18(16):2387-92.

7. Chen HZ, Guo S, Li ZZ, Lu Y, Jiang DS, Zhang R, et al. A critical role for interferon regulatory factor 9 in cerebral ischemic stroke. J Neurosci. 2014;34(36):11897-912. doi: 10.1523/jneurosci.1545-14.2014.

8. Cichoń N, Bijak M, Miller E, Niwald M, Saluk J. Poststroke depression as a factor adversely affecting the level of oxidative damage to plasma proteins during a brain stroke. Oxid Med Cell Longev. 2015;2015:408745. doi: 10.1155/2015/408745.

9. Fischer U, Arnold M, Nedeltchev K, Brekenfeld C, Ballinari $\mathrm{P}$, Remonda L, et al. NIHSS score and arteriographic findings in acute ischemic stroke. Stroke. 2005;36(10):2121-5. doi: 10.1161/01.STR.0000182099.04994.fc.

10. Sulter G, Steen C, De Keyser J. Use of the Barthel index and modified Rankin scale in acute stroke trials. Stroke. 1999;30(8):1538-41. doi: 10.1161/01.str.30.8.1538.

11. Conlan MJ, Rapley JW, Cobb CM. Biostimulation of wound healing by low-energy laser irradiation. A review. J Clin Periodontol. 1996;23(5):492-6. doi: 10.1111/j.1600051x.1996.tb00580.x.

12. Oron U, Yaakobi T, Oron A, Mordechovitz D, Shofti R, Hayam
G, et al. Low-energy laser irradiation reduces formation of scar tissue after myocardial infarction in rats and dogs. Circulation. 2001;103(2):296-301. doi: 10.1161/01.cir.103.2.296.

13. Oron U, Yaakobi T, Oron A, Hayam G, Gepstein L, Rubin O, et al. Attenuation of infarct size in rats and dogs after myocardial infarction by low-energy laser irradiation. Lasers Surg Med. 2001;28(3):204-11. doi: 10.1002/lsm.1039.

14. Annoni JM, Staub F, Bruggimann L, Gramigna S, Bogousslavsky J. Emotional disturbances after stroke. Clin Exp Hypertens. 2006;28(3-4):243-9. doi: 10.1080/10641960600549173.

15. Madhow $U$, Honig ML. MMSE interference suppression for direct-sequence spread-spectrum CDMA. IEEE Trans Commun. 1994;42(12):3178-88. doi: 10.1109/26.339839.

16. Brisdelli F, Bennato F, Bozzi A, Cinque B, Mancini F, lorio R. ELF-MF attenuates quercetin-induced apoptosis in $\mathrm{K} 562$ cells through modulating the expression of $\mathrm{Bcl}-2$ family proteins. Mol Cell Biochem. 2014;397(1-2):33-43. doi: 10.1007/ s11010-014-2169-1.

17. Sulpizio M, Falone S, Amicarelli F, Marchisio M, Di Giuseppe F, Eleuterio $\mathrm{E}$, et al. Molecular basis underlying the biological effects elicited by extremely low-frequency magnetic field (ELF-MF) on neuroblastoma cells. J Cell Biochem. 2011;112(12):3797-806. doi: 10.1002/jcb.23310.

18. Yi G, Wang J, Wei X, Deng B, Tsang KM, Chan WL, et al. Effects of extremely low-frequency magnetic fields on the response of a conductance-based neuron model. Int J Neural Syst. 2014;24(1):1450007. doi: 10.1142/s0129065714500075.

19. Lapchak PA, Wei J, Zivin JA. Transcranial infrared laser therapy improves clinical rating scores after embolic strokes in rabbits. Stroke. 2004;35(8):1985-8. doi: 10.1161/01. STR.0000131808.69640.b7.

20. Detaboada L, Ilic S, Leichliter-Martha S, Oron U, Oron A, Streeter J. Transcranial application of low-energy laser irradiation improves neurological deficits in rats following acute stroke. Lasers Surg Med. 2006;38(1):70-3. doi: 10.1002/ Ism.20256.

21. Ciancarelli I, De Amicis D, Di Massimo C, Carolei A, Ciancarelli MG. Oxidative stress in post-acute ischemic stroke patients after intensive neurorehabilitation. Curr Neurovasc Res. 2012;9(4):266-73. doi: 10.2174/156720212803530717.

22. Hacke W, Schellinger PD, Albers GW, Bornstein NM, Dahlof $B L$, Fulton R, et al. Transcranial laser therapy in acute stroke treatment: results of neurothera effectiveness and safety trial 3, a phase III clinical end point device trial. Stroke. 2014;45(11):3187-93. doi: 10.1161/strokeaha.114.005795.

23. Powers WJ, Rabinstein AA, Ackerson T, Adeoye OM, Bambakidis NC, Becker K, et al. 2018 guidelines for the early management of patients with acute ischemic stroke: a guideline for healthcare professionals from the American Heart Association/American Stroke Association. Stroke. 2018;49(3):e46-e110. doi: 10.1161/str.0000000000000158.

24. Leung MC, Lo SC, Siu FK, So KF. Treatment of experimentally induced transient cerebral ischemia with low energy laser inhibits nitric oxide synthase activity and up-regulates the expression of transforming growth factor-beta 1. Lasers Surg Med. 2002;31(4):283-8. doi: 10.1002/lsm.10096. 